2. The types of wounds encountered and their treatment in the field have been outlined.

3. The results of such treatment and the final visual capabilities of the eyes treated, some two years later have been indicated.

My apologies are due to the many service departments, English, Canadian and American, that I have "badgered" for case records during the past six months.

My thanks are especially due to Sgt. F. Hales and Pte. R. Merrett, R.A.M.C., without whose drive and above all cheerfulness we might never have done the job, even with the help of our innumerable " tonios."

\title{
REFERENCES
}

WÜRDEMANN.-Ophthalmic in juries

Brit. Jl. Ophthal.-February, March, 1944. January, February, March, April and June, 1945.

Contes, F. C.-Ocular Injuries in War. Amer. Jl. Ophthal.

The Refractionist - December, 1944.

STALLARD.-(Personal communication).

\section{CAVERNOUS HAEMANGIOMA OF THE ORBIT SUCCESSFULLY REMOVED BY SHUGRUE'S OPERATION*}

\author{
BY \\ Milroy PaUl \\ PROFESSOR OF SURGERY, UNIVERSITY OF CEYLON
}

THE removal of a retrobulbar intra-orbital tumour is a rare event, which is worthy of record in view of the dangers of injury to the delicate intra-orbital structures. In the recorded cases of successful removal of intra-orbital cavernous haemangiomata, the tumour has been well encapsulated, a factor greatly facilitating the operative procedure. It is also remarkable that there have been no supplying blood vessels of sufficient size to cause appreciable haemorrhage after the enucleation of the tumour.

A retrobulbar intra-orbital tumour could only be exposed through one of the bony walls of the orbit, and although every route has been exploited, the two most commonly used routes are through the roof of the orbit or through its outer wall. The approach through the roof of the orbit is necessarily an intracranial approach, and although the dura mater could be reflected off the bone if there were no intra-cranial extension, it is generally agreed that this route should be reserved for cases in which there

* Received for publication, June 2, 1945. 
has been an extension of the growth through the roof of the orbit. The best known method of approach through the outer wall of the orbit is the Krönlein operation. It is difficult to see how the branches of the facial nerve to the muscles of the eyelids could escape injury when the skin incisions are made, although recorded cases make no mention of paralysis of the orbicularis oculi muscles after the operation. The Shugrue operation (Spaeth, 1939) definitely conserves the branches of the facial nerve supplying the eyelids, and this was felt to outweigh the disadvantage of permanent removal of the outer wall of the orbit entailed in this operation :-

Case Report:-D.M.S. male, Cingalese, aged 52 years, entered the General Hospital, Colombo, on December 11, 1944, on account of gross protrusion of the left eyeball. Eighteen months previously the patient had noted that the vision of his left eye was failing, but he had put this down to advancing age. During the last six months, the left eyeball had begun to protrude, and this had steadily become so much worse that he had been unable to close the lids over the eyeball.

On examination the patient was seen to be an elderly Cingalese labourer, who presented a striking picture from the circumstance

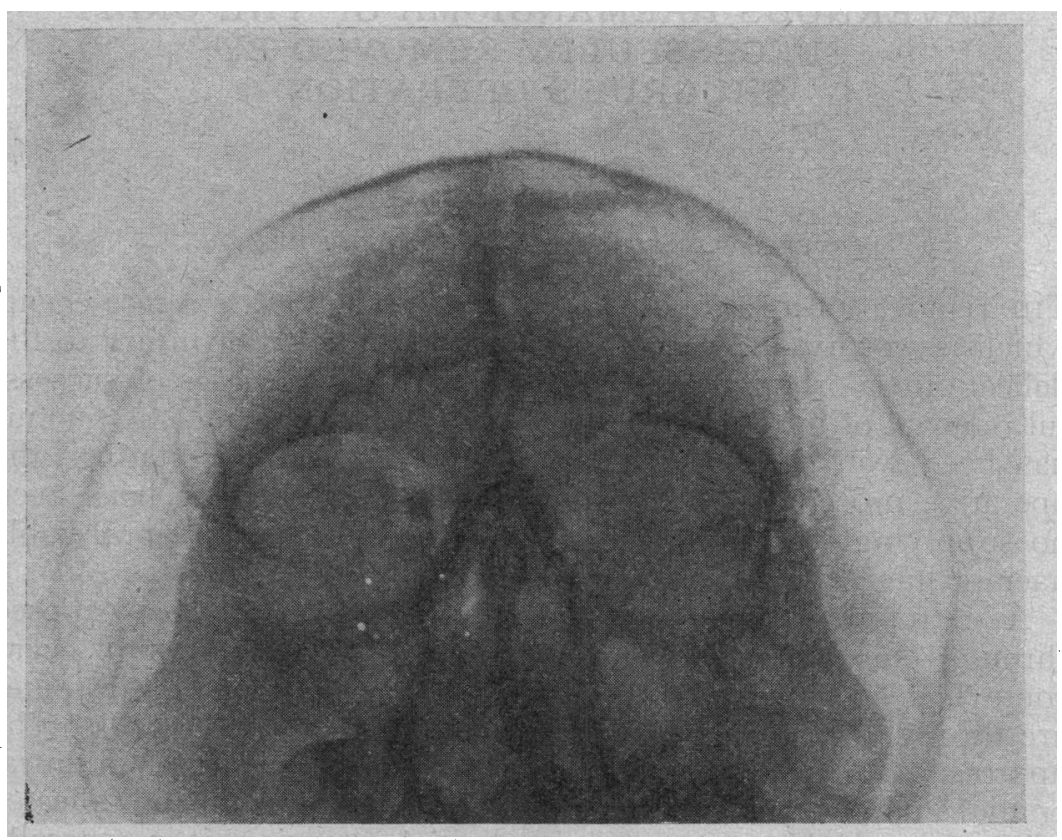

Fig. 1.

X-ray of patient's skull, showing absence of involvement of bone by the tumour. 


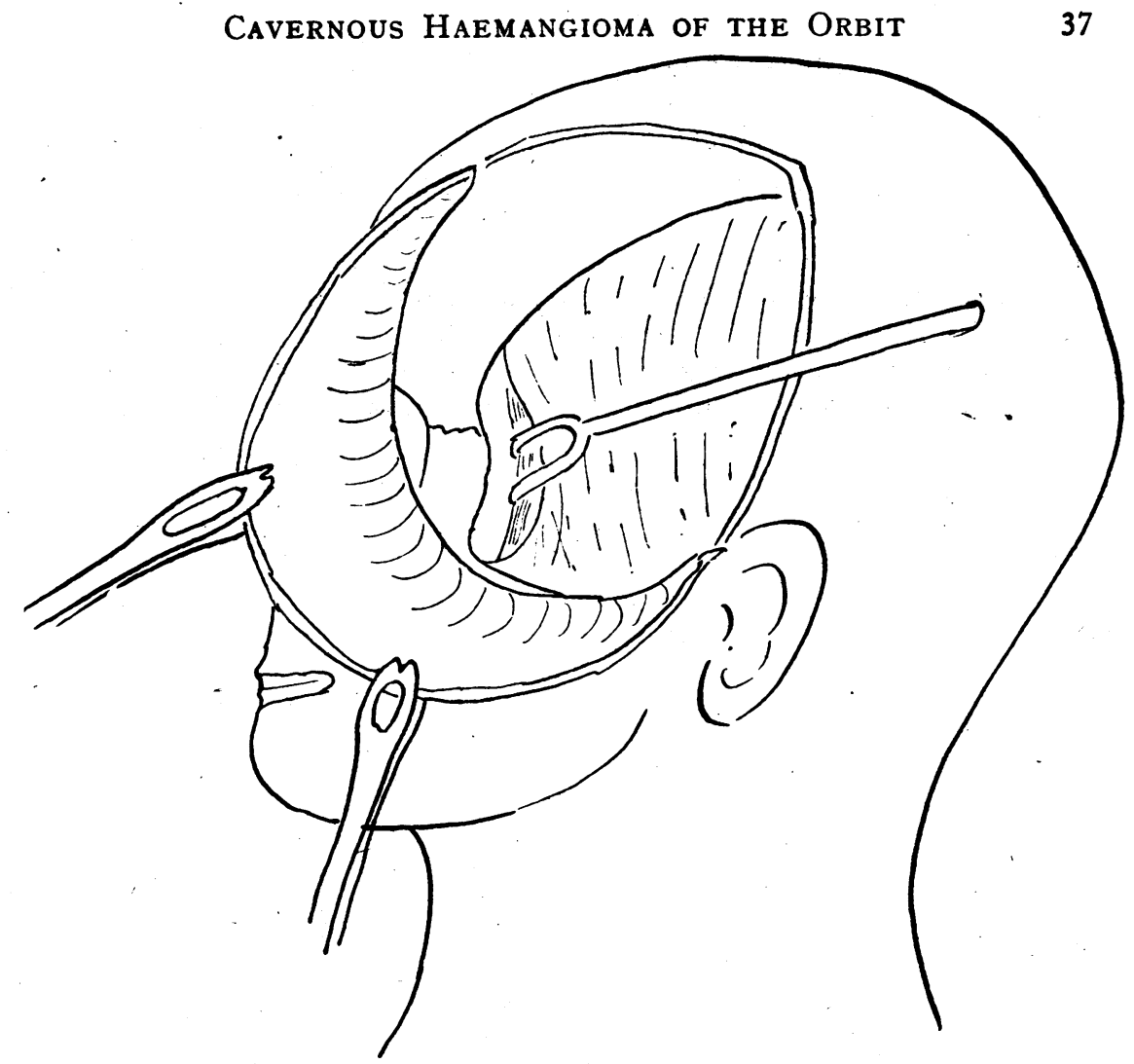

Fig. 2.

Shows exposure of zygomatic bone by Shugrue's operation.

that the left eyeball was almost protruded out of its socket. The ocular conjunctiva was injected, and there was epiphora. There was a cataract in the left eye and the patient was only able to distinguish objects at six inches from this eye. Vision in the right eye was good. The movements of both eyes were normal but there was some limitation of the movements of the left eyeball at its extreme peripheral excursions. The case was referred to Dr. Dadhaboy, Senior Ophthalmic Surgeon of the Ceylon Medical Service who reported as follows:-Incipient cataract in left eye. Fundus and disc normal. Right eye vision $6 / 12$. Left eye vision $3 / 60$. The rest of the report covered the points already elaborated. Dr. Dadhaboy was of opinion that the poor vision of the left eye was due to the cataract. It was clear that the patient had a retrobulbar intra-orbital tumour which had not infiltrated the extra ocular muscles. The Wassermann and Khan reactions were negative. An X-ray picture showed no evidence of involvement of the cranial bones by the growth and the air sinuses were normal. Fig. 1. 
Operation under endotracheal ether anaesthesia on January 8 , 1945.

A curved scalp incision was made from just in front of the tragus of the ear up almost to the vertex of the skull, and then forwards to the junction of the hairline with the forehead. The flap was turned downwards over the zygoma, particular care being taken to avoid injury to the temporal branches of the facial nerve by keeping the plane of the dissection close to the temporal fascia. The temporal fascia was incised behind the posterior border of the zygomatic bone, and the temporal muscle was dissected off

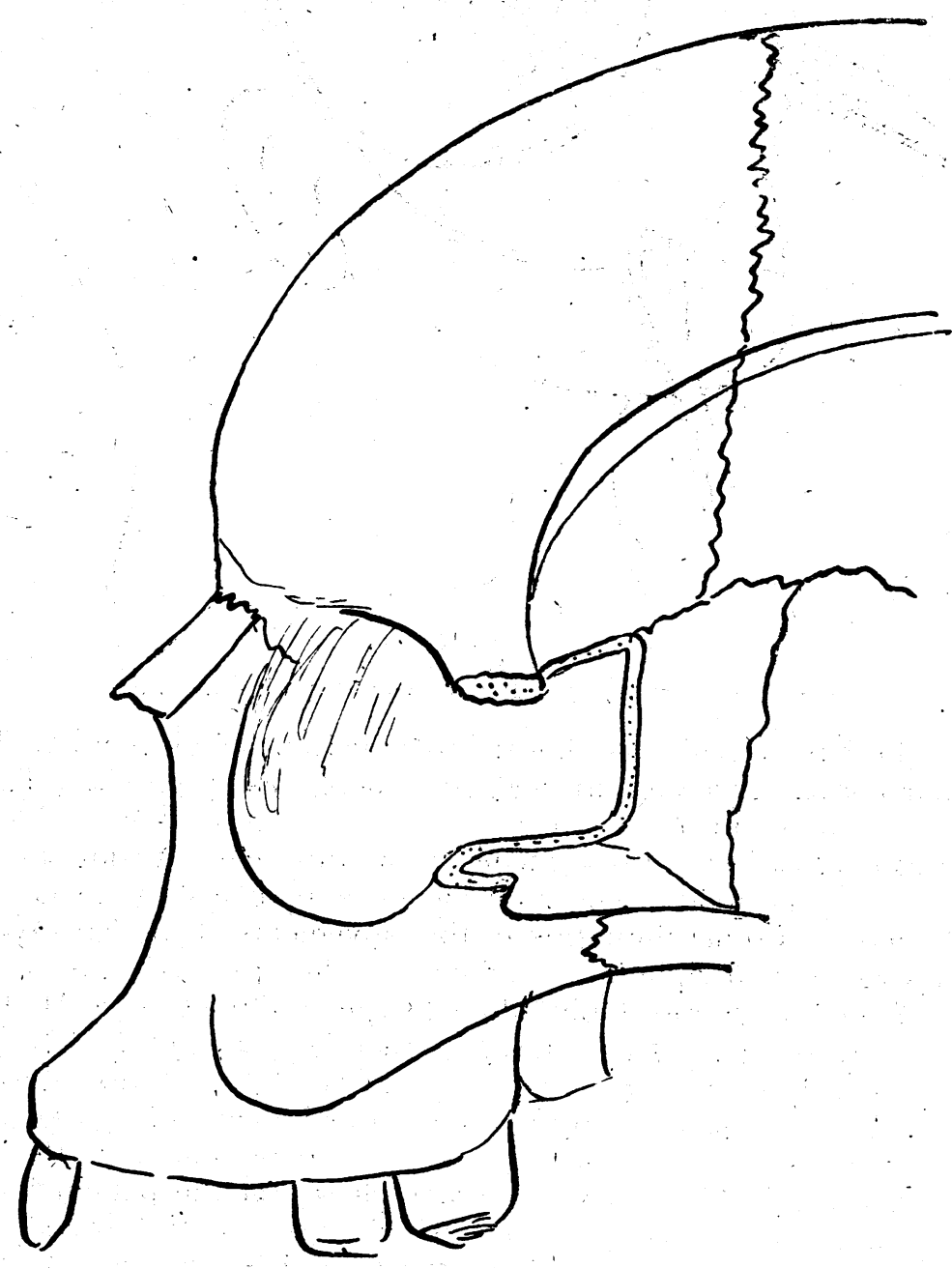

FIG. 3.

Diagram of patient after operation showing extent of bone removed in ,Shugrue's operation. 
and retracted away from the zygomatic bone. Fig. 2. The overhanging posterior edge of the zygomatic bone was removed with Horsley's nibbling forceps and the lateral wall of the orbit exposed. As the tumour was expected to be large, it was decided to remove the outer rim together with the lateral wall of the orbit, and this was done by continuing the removal of bone with the Horsley's forceps. (Fig. 3 and 4.)

Deep to the lateral rectus muscle was a plum coloured ovoid tumour, the size of a marble, lying within the cone of the extra

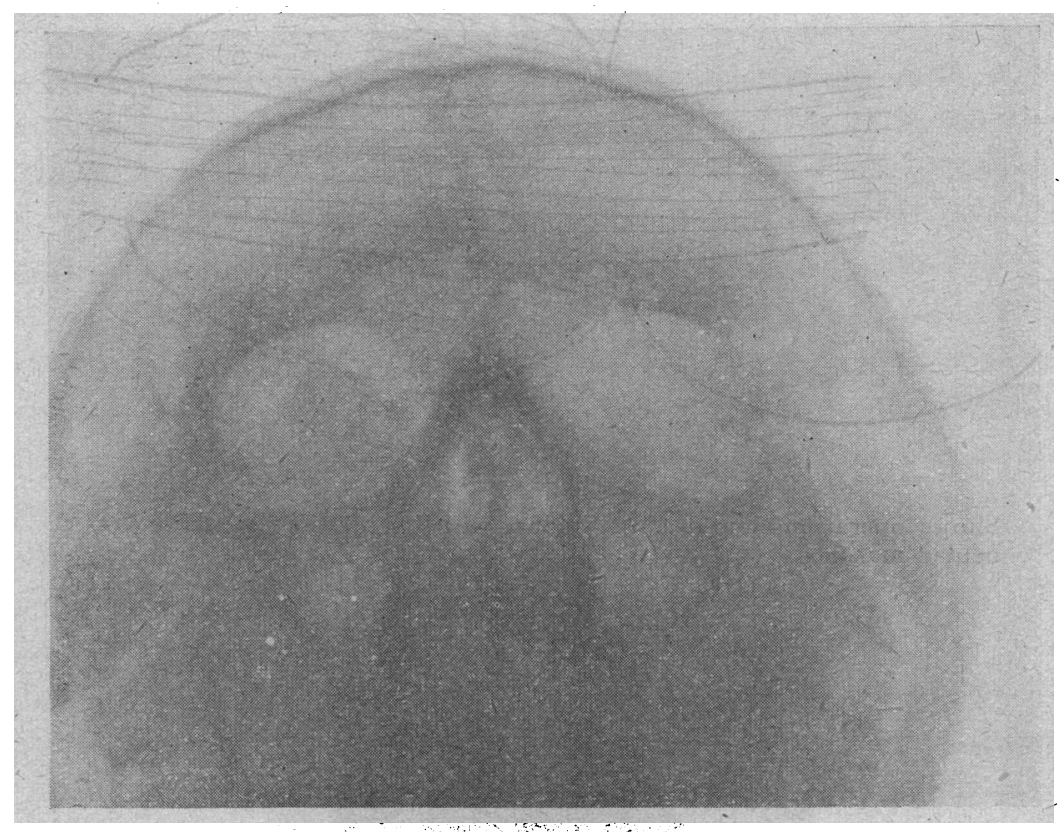

FIG. 4.

Shows extent of bone removed in Shúgrue's operation

ocular muscles with its anterior pole resting on the posterior pole of the eyeball, Fig. 5. The connective tissues between the superior rectus and the lateral rectus muscles were gently separated, and the tumour was enucleated from its bed by careful blunt dissection with the blades of an artery forceps. The tumour shelled out readily (Fig. 6) and there was surprisingly little haemorrhage from its bed. The incision in the temporal fascia was sutured and the skin wound was closed. The old man stood the operation well, and the proptosis was now no longer present. Some hours after operation there was marked chemosis, which gradually subsided in the next few days. At this time it was noted that outward movement of the left eyeball only occurred up to the neutral 
position and that there was some ptosis of the upper eye-lid which was not however sufficient to cover the pupil even on looking upwards. Dr. Dadhaboy reported that vision was the same as before the operation, and advised that the patient be referred to him at a later date for the cataract operation.

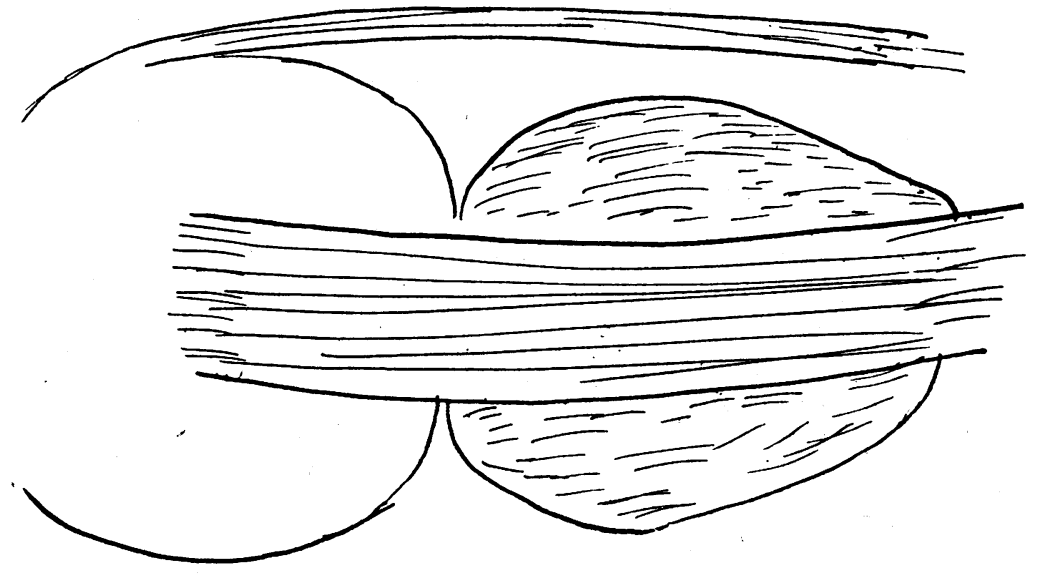

FIG. 5.

Shows operation view of the tumour, with its relations to the extraocular muscles.

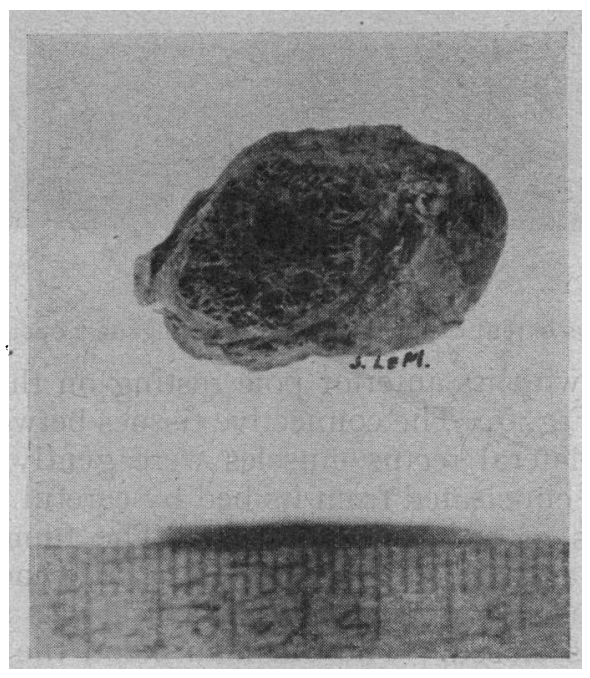

Fig. 6.

Photograph of tumour. A piece of tumour has been removed to show the internal structure. Large spaces filled with blood clot are seen on the cut surface. (The tumour was photographed a month after operation, and it has shrunk considerably). 


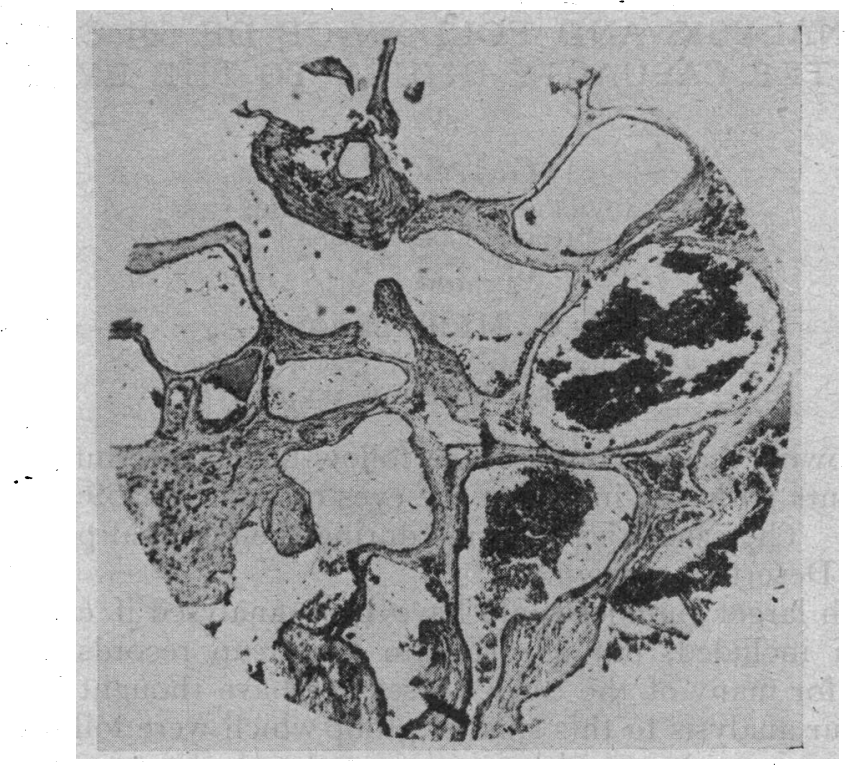

Fig. 7.

Micro-photograph showing the large blood containing spaces lined by endothelium.

Microscopic examination shows the tumour to be composed of cavernous blood containing spaces lined by a well-developed layer of endothelium. This layer of endothelium is surrounded by plain muscle fibres in the case of some of the spaces. Separating the endothelial walls is a layer of fibrous tissue which contains fat cells and well-formed blood vessels in some areas, Fig. 7.

The patient was well pleased with the result of the operation, despite the limitation in movements which had resulted and he left hospital on February 23, 1945.

Commentary.-Reference to recorded cases of successful removal of tumours through the external wall of the orbit shows that weakness of the lateral rectus muscle is a not uncommon sequel. (Crawford et al, 1943, Stallard, 1938.) It is possible that the weakness in this case would improve as time went on, as would also the weakness of the upward movements of the upper eyelid. The experience in this case with Shugrue's operation suggests that excision of the outer wall of the orbit does not in itself appreciably interfere with the function of the eye, nor is the deformity particularly noticeable. The exposure of the tumour was particularly good, and the risk of operative trauma to the intra-orbital structures is thereby minimised.

\section{REFERENCES}

CRAWFORD, T., KING E. F. and RODGERS, H: W.-Haemangioma of the orbit, removed by operation. Brit. Jl. Ophthal., p. $61,1943$.

SHUGRUE'S OPERATION.- Principles and practice of ophthalmic surgery, p. 68. Spaeth, E. B., Henry Kimpton, 1939.

STALLARD, H. B.-Cavernous haemangioma of the orbit, successfully removed by Krönlein's operation. Lancet, p. 131, January 15, 1938. 